\title{
Evaluation of possible factors affecting contrast sensitivity function in patients with primary Sjögren's syndrome
}

\author{
A avaliação dos possíveis fatores que afetam a função de sensibilidade ao contraste em pacientes com \\ síndrome de Sjögren primária
}

Sedat Arikan ${ }^{1}$, Ferhat Gokmen², Arzu Taskiran Comez ${ }^{1}$, Baran Gencer ${ }^{1}$, Selcuk Kara $^{1}$, Ayla Akbal ${ }^{2}$

\begin{abstract}
Purpose: The contrast sensitivity (CS) function in patients with primary Sjögren's syndrome (pSS) may be impaired either frequently as a result of dry eye diseases or rarely as a result of optic neuropathy. In this study, we aimed to evaluate the CS function in pSS patients as well as to assess corneal aberrations and thickness of the peripapillary retinal nerve fiber layer ( $p R N F L$ ).

Methods: Fourteen eyes of 14 pSS patients (pSS group) and 14 eyes of 14 healthy participants (control group) were subjected to assessment of CS at the spatial frequencies of 1.5, 3.0,6.0,12, and 18 cycles/degree (cpd) using a functional visual acuity contrast test (FACT); measurement of corneal high-order aberrations (HOAs) in terms of coma-like, spherical-like, and total HOAs using Scheimpflug corneal topography; and measurement of the thickness of both the macular ganglion cell-inner plexiform layer (mGCIPL) and pRNFL in all quadrants using optical coherence tomography. None of the participants were under treatment with artificial tears. Results: The results of the CS test did not differ between the 2 groups at all spatial frequencies ( $p>0.05)$. In addition, there were no statistically significant differences between the 2 groups in terms of corneal HOAs ( $p>0.05)$ and thickness of $\mathrm{mGCIPL}$ ( $p>0.05)$. However, among all quadrants, only the inferior quadrant of $p R N F L$ in pSS patients was statistically significantly thinner than that in the healthy participants $(p=0.04)$

Conclusions: The CS function in pSS patients can be maintained with normal thickness of both pRNFL and MGCIPL and with lack of increased corneal HOAs, which may be present even in the absence of artificial tear usage.
\end{abstract}

Keywords: Sjogren's syndrome; Corneal wavefront aberration; Dry eye diseases; Optic disk/pathology; Optical coherence tomography

\section{RESUMO}

Objetivo: A função de sensibilidade ao contraste em pacientes com síndrome de Sjögren primário (pSS) pode ser prejudicada, quer frequentemente como resultado de doenças do olho seco, ou mais raramente como um resultado de neuropatia óptica. Neste estudo, objetivamos avaliar a função de sensibilidade ao contraste de pacientes com pSS, além da avaliação das aberrações da córnea e a espessura da camada de fibras nervosas da retina ( $p R N F L)$.

Métodos: Catorze olhos de 14 pacientes com pSS e 14 olhos de 14 participantes saudáveis foram submetidos, respectivamente, à avaliação do teste de sensibilidade aos contrastes (CS) nas frequências espaciais de 1,5, 3,0, 6,0, 12 e 18 ciclos/grau (cpd), utilizando teste de contraste acuidade visual funcional (FACT); a medida das aberrações de alta ordem da córnea (HOAs) em termos de coma, aberrações esféricas e aberrações totais, utilizando topografia corneana por Scheimpflug; e medida de espessura da camada de macular de células ganglionares plexiforme interna ( $\mathrm{mGCIPL)} \mathrm{e} \mathrm{a} \mathrm{espessura}$ de pRNFL em todos os quadrantes usando tomografia de coerência óptica. Nenhum dos participantes estava sob tratamento com lágrimas artificiais.

Resultados: Oteste CS em pacientes pSS não diferiu do que o teste CS em participantes saudáveis em todas as frequências espaciais $(p>0,05)$. Não houve também nenhuma diferença estatisticamente significativa entre os dois grupos em termos de HOAs da córnea ( $p>0,05)$, eespessura de MGCIPL $(p>0,05)$. No entanto, entre todos os quadrantes, apenas o quadrante inferior da pRNFL em pacientes pSS foi significativamente mais fino que o quadrante inferior da pRNFL em participantes saudáveis $(p=0,04)$.

Conclusões: A função de CS em doentes com pSS pode ser mantida em condições de ambas as espessuras normais de PRNFL e MGCIPL, assim como nas condições de falta de aumento HOAs da córnea, que pode ser mantida, mesmo na ausência do uso de lágrimas artificiais.

Descritores: Síndrome de Sjögren; Aberrações de frente de onda da córnea; Síndrome de olho seco; Disco óptico/patologia; Tomografia de coerência óptica

\section{INTRODUCTION}

Primary Sjögren's syndrome (pSS) is a chronic autoimmune disease characterized by dysfunction of the lacrimal and salivary glands, leading to keratoconjunctivitis sicca and xerostomia in the absence of other coexisting connective tissue diseases. Dysfunction of both the lacrimal and salivary glands in pSS patients arises from destructive mononuclear infiltration of the acinar and ductal epithelia of these glands. As dry eye, which is the hallmark ocular manifestation of pSS, can frequently compromise the quality of vision due to irregularities of the ocular surface, nevertheless, efforts are commonly directed toward improvement of the ocular surface structures of these patients in ophthalmic practice.
However, it has been reported that pSS patients may also suffer from visual acuity changes or visual quality disturbances as a result of optic neuropathy, which may occur before or at the same time as the diagnosis of $\mathrm{pSS} \mathrm{S}^{(1-3)}$. Thus, when evaluating the visual quality of pSS patients, both functional and morphological analyses of the optic nerve should also be performed in addition to examination of the ocular surface structures. In this context, along with optical coherence tomography (OCT), which allows assessment of the morphological features of the optic nerve to some extent, a contrast sensitivity (CS) test can be beneficial in the assessment of the functional feature of the optic nerve, because it may enable determination of visual disturbances, even in the early stages of optic nerve diseases ${ }^{(4,5)}$. In some

Submitted for publication: November 25, 2014

Accepted for publication: February 25, 2015

Department of Ophthalmology, Canakkale Onsekiz Mart University School of Medicine, Canakkale, Turkey.

Department of Physical Medicine and Rehabilitation, Canakkale Onsekiz Mart University School of Medicine, Canakkale, Turkey.

Funding: No specific financial support was available for this study.

Disclosure of potential conflicts of interest: None of the authors have any potential conflict of interest to disclose.

Corresponding author: Sedat Arikan. Department of Ophthalmology - Canakkale Onsekiz Mart. Universitesi Tip Fakultesi - Goz Hastalıkları AD - Canakkale - Turkey - E-mail: drsarikan@gmail.com 
clinical conditions associated with optic nerve involvement, patients can show disability with their low-contrast visual acuities, while their high-contrast visual acuities remain unaffected ${ }^{(6)}$. Therefore, patients who may be at risk of optic neuropathy, such as those with pSS, should also be examined using a CS test, although they may have completely normal visual acuity levels according to the Snellen chart.

In the present study, to evaluate the effects of these possible factors on the CS function in pSS patients, we assessed the CS of pSS patients using the functional visual acuity contrast test (FACT) and evaluated corneal high-order aberrations (HOAs) using Scheimpflug corneal topography and the thickness of the peripapillary retinal nerve fiber layer (pRNFL) and macular ganglion cell-inner plexiform layer ( $\mathrm{mGCIPL)}$ using OCT.

\section{METHODS}

This prospective and comparative study was conducted at the Ophthalmology Department of Canakkale Onsekiz Mart University School of Medicine. The study protocol followed the Declaration of Helsinki for research involving human subjects and was approved by the local ethics committee. Healthy subjects and patients diagnosed with pSS who had been followed-up by the Physical Medicine and Rehabilitation Department of Canakkale Onsekiz Mart University School of Medicine were recruited for the study. Diagnosis of pSS was made on the basis of suggestions of the American-European study group on the classification criteria for Sjögren's syndrome ${ }^{(7)}$. As per the American-European study group, "the presence of any 4 of the 6 items is indicative of primary SS, as long as either item IV (Histopathology) or VI (Serology) is positive"; accordingly, patients who met these criteria of pSS were included in this study.

Written informed consent was obtained from both pSS patients and healthy subjects who agreed to participate in this study as volunteers. Then, comprehensive ophthalmologic examination consisting of the measurement of best-corrected visual acuity (BCVA) and intraocular pressure, slit-lamp biomicroscopy, and funduscopic examination was performed for all participants.

The exclusion criteria for this study were established as having any history of previous ocular surgery or eye trauma, contact lens use, cataract diagnosis, corneal and conjunctival diseases, ocular inflammatory diseases, glaucoma, retinal diseases, chronic eye drop usage including artificial tears, systemic diseases except pSS, and BCVA below 20/20. The participants who met the eligibility criteria were subjected to corneal topographic assessments for measuring the root mean square (RMS) values of corneal HOAs including coma-like, spherical-like, and total HOAs using a Scheimpflug camera (Sirius version 1.2 , CSO, Firenza, Italy); measurement of the thickness of pRNFL in the superior, inferior, nasal, and temporal quadrants of the optic nerve; measurement of the thickness of MGCIPL using Cirrus HD-OCT 4000 (Carl Zeiss Meditec Inc., Dublin, CA); and measurement of the level of CS at a number of different spatial frequencies such as 1.5, 3.0, 6.0, 12, and 18 cycles/degree (cpd) using FACT (OPTEC 6500 Contrast Sensitivity View-in Tester, Stereo Optical Company, Inc., Chicago, IL) in the day and without-glare mode. As described previously ${ }^{(8,9)}$, the corneal transparency of the participants was assessed by measuring the percentage of light scatter density from the central cornea; for this, we used the histogram mode of the Scheimpflug camera.

With respect to statistical analysis, the Mann-Whitney $U$ test was performed using SPSS version 13 (Statistical Package for Social Sciences Inc., Chicago, IL, USA) in order to evaluate the relationships between the pSS patients and healthy subjects in terms of the thickness of pRNFL and $\mathrm{MGCIPL}$, RMS values of corneal HOAs, and level of CS. A $p$-value of $\leq 0.05$ was accepted as statistically significant.

\section{RESULTS}

Fourteen right eyes of 14 female pSS patients and 14 right eyes of 14 female healthy subjects were enrolled into this study. The partici- pants were divided into 2 groups: the pSS group comprising the pSS patients and the control group comprising the healthy subjects. The mean duration of disease was $5.7 \pm 5$ (1-20) years in the pSS group. All pSS patients who participated in the current study were under treatment with hydroxychloroquine $(\mathrm{HQ})$; the mean duration of $\mathrm{HQ}$ usage was $3.8 \pm 2.8$ (1-10) years. The mean logMAR value of the BCVA was 0 in both groups. The mean age of the pSS group and control group was statistically similar [51.3 $\pm 5.7(45-64)$ years and $49.2 \pm$ 5.9 (39-58) years, respectively] ( $p>0.05$ ). There were no statistically significant differences between the 2 groups in terms of the spherical equivalent value $[0.47 \pm 0.79(0.00-2.50) \mathrm{D}$ and $0.46 \pm 0.53$ (0.00-1.50) $D$, respectively] $(p>0.05)$. In the pSS group, 5 and 2 patients were positive for the anti-Ro antibody and anti-La antibody, respectively, whereas 4 patients were positive for both anti-Ro and anti-La antibodies; 3 patients were negative for both anti-Ro and anti-La antibodies. In the control group, all participants were negative for both anti-Ro and anti-La antibodies. All relevant clinical data for the pSS patients is presented in table 1.When we compared the thickness of pRNFL in all quadrants, only the inferior quadrant of pRNFL in the pSS group was statistically significantly thinner than that in the control group $(p<0.05)$ (Figure 1). There were no statistically significant differences between the 2 groups in terms of the CS function at all spatial frequencies such as 1.5, 3.0,6.0, 12, and $18 \mathrm{cpd}(\mathrm{p}>0.05)$ and in terms of the RMS values of coma-like, spherical-like, and total HOAs ( $p>0.05$ ) (Figure 2 and Figure 3, respectively). The thickness of $\mathrm{MGCIPL}$ in the pSS group and control group was similar [85.7 \pm 3.7 (80-92) $\mu \mathrm{m}$ and $85.8 \pm 4.2(81-92) \mu m$, respectively] $(p>0.05)$.

Table 1. All relevant clinical data of primary Sjögren's syndrome (pSS) patients

\begin{tabular}{|c|c|c|c|}
\hline & $\begin{array}{c}\text { pSS group } \\
(\mathrm{N}=14)\end{array}$ & $\begin{array}{l}\text { Control group } \\
\qquad(\mathrm{N}=14)\end{array}$ & p-value \\
\hline Schirmer I test (mm, mean $\pm \mathrm{SD}$ ) & $7.8 \pm 4.3$ & $16.2 \pm 2.7$ & $\mathrm{p}<0.0001^{*}$ \\
\hline TBUT (seconds, mean \pm SD) & $9.9 \pm 3.5$ & $14.5 \pm 2.4$ & $p=0.001^{*}$ \\
\hline Salivary gland focus score (mean \pm SD) & $1.07 \pm 0.99$ & $-\cdots$ & \\
\hline BCVA (logMAR) & 0 & 0 & \\
\hline Subjects anti-Ro ab + (n) & 4 & 0 & \\
\hline Subjects anti-La ab + (n) & 2 & 0 & \\
\hline Subjects anti-Ro + and anti-La ab + (n) & 4 & 0 & \\
\hline Subjects with neuropathy (n) & 0 & 0 & \\
\hline Cornea light scatter $(\%$, mean \pm SD) & $21.1 \pm 2.5$ & $20.9 \pm 2.5$ & $p=0.9$ \\
\hline
\end{tabular}

TBUT= tear film break-up time; BCVA= best-corrected visual acuity.

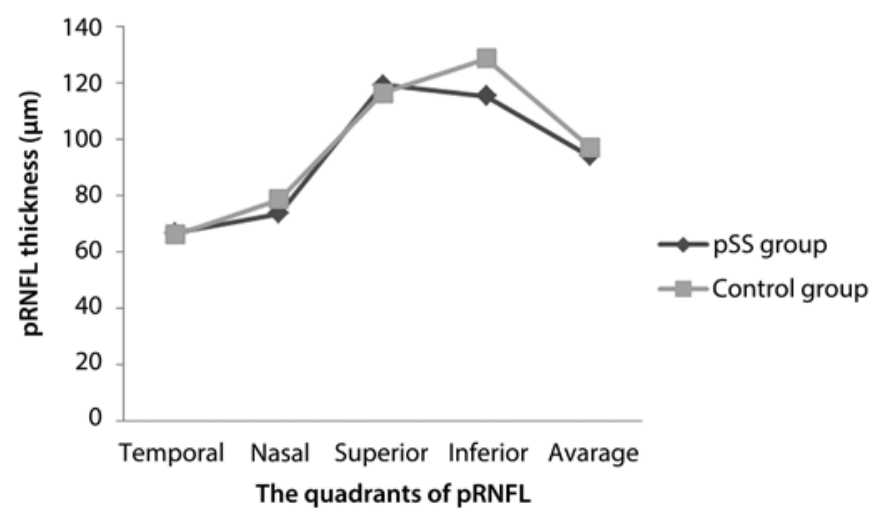

Figure 1. Mean thickness of the peripapillary retinal nerve fiber layer (pRNFL) in all quadrants in both groups. Note that among all quadrants of pRNFL, a significant difference between the 2 groups was observed only in the inferior quadrant. 


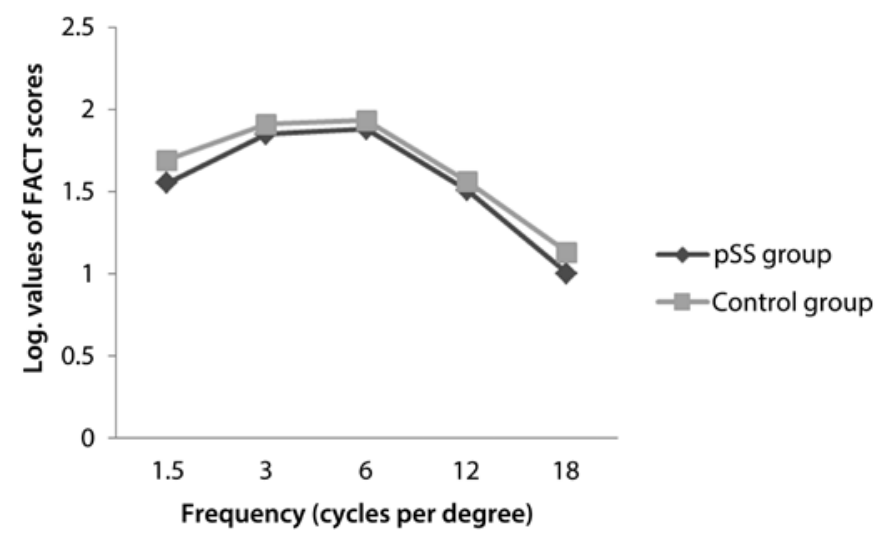

Figure 2. The mean functional visual acuity contrast test (FACT) scores in terms of logarithmic values between the 2 groups were nearly similar at all spatial frequencies.

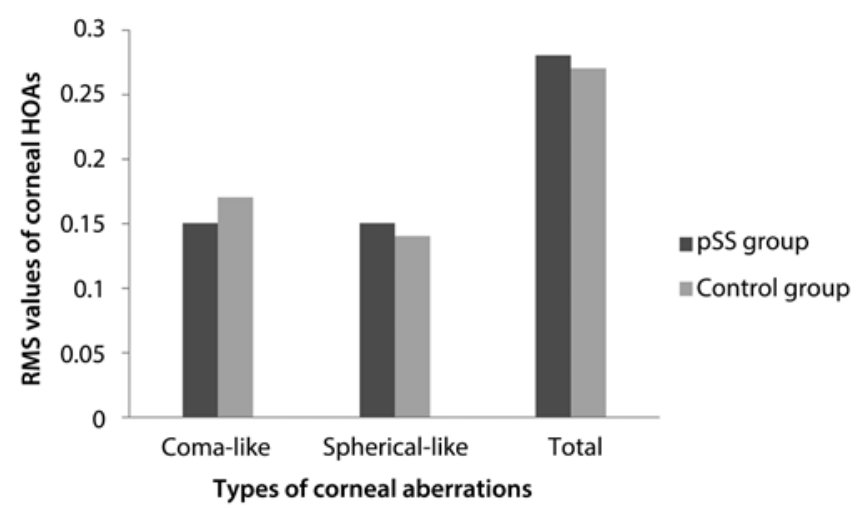

Figure 3. The mean root mean square (RMS) values of all types of corneal high-order aberrations (HOAs) were similar between the 2 groups.

\section{DISCUSSION}

The B-cell activating factor of the tumor necrosis factor family (BAFF) is considered to be an important cytokine in the pathogenesis of autoantibody-associated immune pathologies, and it has an important role in B-cell maturation, plasma cell survival, and autoantibody production. Studies that have investigated the pathophysiological mechanisms of pSS have also revealed the significant effect of BAFF on the development of pSS(10,11). Overproduction of BAFF in transgenic mice has been shown to lead to pathological findings resembling those observed in $\mathrm{pSS}^{(12)}$. On the other hand, higher levels of BAFF that have been detected either in the serum or saliva of pSS patients may support this association in humans ${ }^{(13,14)}$.

Besides playing a crucial role in salivary gland inflammation and in the pathophysiological mechanisms of pSS, the increased expression of BAFF may also participate in ocular surface disorders that are frequently observed in pSS patients. Mariette et al. reported enhanced levels of BAFF mRNA both in the salivary glands and ocular surface of pSS patients ${ }^{(15)}$. Higher levels of BAFF have previously been observed in the cerebrospinal fluid of patients with multiple sclerosis (MS) or neuromyelitis optica $(\mathrm{NMO})^{(16)}$. In addition, a strong relationship between pSS and NMO had been demonstrated in numerous case reports ${ }^{(17-21)}$. Thus, we postulated that apart from participating in pSS, BAFF may also be responsible for the development of optic neuropathy in pSS patients.

In the literature, although the mechanism of optic neuropathy in pSS patients has been attributed to vasculitis (22), we believe that the increased expression of BAFF may additionally participate in the optic nerve damage of pSS patients in 2 ways. First, the increased expression of BAFF may contribute to optic nerve damage by modulating the production levels of autoantibodies such as anti-Ro and anti-La, which are the hallmarks of pSS. It has been reported previously that anti-Ro autoantibodies can play a role in mediating or potentiating vascular injury in the central nervous system ${ }^{(23)}$. A study by Yang et al. indicated that these autoantibodies may also lead to improper apoptotic removal of the retinal ganglion cells (RGCs) by binding to the apoptotic RGCs, resulting in optic nerve damage ${ }^{(24)}$. Furthermore, in the same study, according to the OCT findings of pSS patients, a correlation was demonstrated between the thinning of PRNFL and MGCIPL and increased numbers of autoantibodies such as anti-Ro and anti-La ${ }^{(23)}$. Second, increased serum levels of BAFF may also lead to optic nerve damage by inducing the serum levels of anti-aquaporin-4 antibody (anti-AQP4), which is an important antibody in the development of $\mathrm{NMO}^{(25)}$; overproduction of anti-AQP4 may result in the exposure of neurons to the cytotoxic effects of increased levels of glutamate ${ }^{(26)}$

The optic neuropathy observed in pSS patients can sometimes begin as an initial manifestation even in the absence of xerostomia and dry eye symptoms ${ }^{(1)}$; therefore, along with observing the ocular surface structures, these patients should also be evaluated in terms of their optic nerve functions. For this, the CS test can be a valuable method, as it allows detection of visual quality disturbances that arise from optic nerve dysfunction even in the early phases of the associated diseases. However, the CS test in pSS patients can additionally be impaired by an increased amount of corneal HOAs due to dry eye disease ${ }^{(27)}$. Therefore, this factor should be taken into consideration when evaluating the CS function in pSS patients.

Zhang et al. reported a modest effect of instilling artificial tears on CS in pSS patients, primarily at medium spatial frequencies ${ }^{(28)}$. In this current study, although none of the participants were using artificial tears, there were no significant differences between the pSS group and control group either in terms of CS tests measured at all spatial frequencies or in terms of total, coma-like, and spherical-like HOAs. These similar results may be attributed to the use of HQ in pSS patients, because the alleviating effect of $\mathrm{HQ}$ (reducing the levels of BAFF in the tear fluid of pSS patients) has been demonstrated in a previous study ${ }^{(29)}$. In another study, the beneficial effect of HQ on xerostomia has also been demonstrated in pSS patients ${ }^{(30)}$.

In this current study, although we could not measure the levels of BAFF in the serum of the participants, we postulated that the similarity between the pSS patients and healthy subjects with respect to the thickness of mGCIPL and PRNFL, except in the inferior quadrant, may have been a consequence of the reduced effects of $\mathrm{HQ}$ on the serum levels of BAFF in pSS patients ${ }^{(31)}$. This association may also be supported by the findings of Yang et al. who found significant thinning of pRNFL in both the inferior and temporal quadrants as well as the thinning of $\mathrm{MGCIPL}$ in nearly all quadrants except the superonasal portion of the macula in pSS patients not under treatment with $\mathrm{HQ}^{(21,24)}$. In the current study, we determined that significant thinning of pRNFL in the inferior quadrant in pSS patients may have arisen from mild macular toxicity of $\mathrm{HQ}$; this finding agreed with that reported by Pasadhika ${ }^{(32)}$. Based on these findings, it may be postulated that pSS patients who are under treatment with $\mathrm{HQ}$ may also be protected from optic nerve damage apart from corneal surface irregularities. Moreover, it may be hypothesized that $\mathrm{HQ}$ has a possible effect on preventing relapses of MS by reducing the levels of BAFF(33). However, these hypotheses need to be clarified by further studies.

Because this study was planned for the evaluation of possible factors that may affect the CS function in pSS patients and there were only 14 patients who had been followed-up in our faculty, we could not involve additional pSS patients, particularly who were not under treatment with $\mathrm{HQ}$. In this study, we could not measure the serum levels of BAFF in the participants; we consider this to be another major limitation of this study. However, we believe that the current 
study provides interesting associations related to pSS patients, which should be further evaluated in future studies.

In conclusion, the CS function in pSS patients can be maintained with normal thicknesses of pRNFL and MGCIPL and lack of increased corneal HOAs even in the absence of artificial tear usage. However, further studies involving larger sample sizes are required for verifying these associations.

\section{REFERENCES}

1. Wise CM, Agudelo CA. Optic neuropathy as an initial manifestation of Sjögren's syndrome. J Rheumatol. 1998;15(5):799-802.

2. Molina R, Provost TT, Alexander EL. Peripheral inflammatory vascular disease in Sjögren's syndrome. Association with nervous system complications. Arthritis Rheum 1985:28(12):1341-7.

3. Alexander EL, Malinow K, Lejewski JE, Jerdan MS, Provost TT, Alexander GE. Primary Sjögren's syndrome with central nervous system disease mimicking multiple sclerosis. Ann Intern Med. 1986;104(3):323-30.

4. Ross JE, Bron AJ, Reeves BC, Emmerson PG. Detection of optic nerve damage in ocular hypertension. Br J Ophthalmol. 1985;69(12):897-903.

5. Di Leo MA, Caputo S, Falsini B, Porciatti V, Minnella A, Greco AV, et al. Nonselective loss of contrast sensitivity in visual system testing in early type I diabetes. Diabetes Care. 1992;15(5):620-5.

6. Beden Ü, Kaya S, Yeter V, Erkan D. Contrast sensitivity of thyroid associated ophthalmopathy patients without obvious optic neuropathy. Scientific World J. 2013;2013: 943789. doi: 10.1155/2013/943789.

7. Vitali C, Bombardieri S, Jonsson R, Moutsopoulos HM, Alexander EL, Carsons SE, et al. Classification criteria for Sjögren's syndrome: a revised version of the European criteria proposed by the American-European Consensus Group. Ann Rheum Dis. 2002;61 (6): 554-8.

8. O'Donnell C, Wolffsohn JS. Grading of corneal transparency. Cont Lens Anterior Eye. 2004;27(4):161-70

9. Smith GT, Brown NA, Shun-Shin GA. Light scatter from the central human cornea. Eye (Lond). 1990;4(Pt 4):584-8.

10. Martel C, Jauberteau MO, Vidal E, Fauchais AL. [Pathophysiology of primary Sjögren's syndrome]. Rev Med Interne. 2014;35(8):524-30. French.

11. Kroese FG, Abdulahad WH, Haacke E, Bos NA, Vissink A, Bootsma H. B-cell hyperactivity in primary Sjögren's syndrome. Expert Rev Clin Immunol. 2014;10(4):483-99.

12. Groom J, Kalled SL, Cutler AH, Olson C, Woodcock SA, Schneider P, et al. Association of BAFF/BLyS overexpression and altered B cell differentiation with Sjögren's syndrome. J Clin Invest. 2002;109(1):59-68. Comment in: J Clin Invest. 2002;109(1):17-8.

13. Kiyama K, Kawabata D, Hosono Y, Kitagori K, Yukawa N, Yoshifuji H, et al. Serum BAFF and APRIL levels in patients with lgG4-related disease and their clinical significance. Arthritis Res Ther. 2012;14(2):R86.

14. Ittah M, Miceli-Richard C, Eric Gottenberg J, Lavie F, Lazure T, Ba N, et al. B cell-activating factor of the tumor necrosis factor family (BAFF) is expressed under stimulation by interferon in salivary gland epithelial cells in primary Sjögren's syndrome. Arthritis Res Ther. 2006:8(2):R51.
15. Candon S, Gottenberg JE, Bengoufa D, Chatenoud L, Mariette X. Quantitative assessment of antibodies to ribonucleoproteins in primary Sjögren syndrome: correlation with B-cell biomarkers and disease activity. Ann Rheum Dis. 2009;68(7):1208-12.

16. Wang H, Wang K, Zhong X, Qiu W, Dai Y, Wu A, et al. Cerebrospinal fluid BAFF and APRIL levels in neuromyelitis optica and multiple sclerosis patients during relapse. J Clin Immunol. 2012;32(5):1007-11.

17. Shimode K, Kobayashi S, Kitani M, Okada K, Tsunematsu T. [Optic neuritis in primary Sjögren's syndrome]. Clin Neurol. 1986;26(5):433-6. Japanese.

18. Tesar JT, McMillan V, Molina R, Armstrong J. Optic neuropathy and central nervous system disease associated with primary Sjögren's syndrome. Am J Med. 1992:92(6): 686-92.

19. Kadota Y, Tokumaru AM, Kamakura K, Kohyama S, Okizuka H, Kaji T, et al. Primary Sjögren's syndrome initially manifested by optic neuritis: MRI findings. Neuroradiology. 2002;44(4):338-41.

20. Harada T, Ohashi T, Miyagishi R, Fukuda H, Yoshida K, Tagawa Y, et al. Optic neuropathy and acute transverse myelopathy in primary Sjögren's syndrome. Jpn J Ophthalmol. 1995;39(2):162-5.

21. Gökçay F, Celebisoy N, Gökçay A, Kabasakal Y, Oder G. Primary Sjögren's syndrome presenting as neuromyelitis optica. Pediatr Neurol. 2007;36(1):58-60.

22. Sasaki T, Niikawa K, Onodera S, Umenai T, Suzuki T, Uchimi M, et al. An autopsy case of Sjögren's syndrome with a clinical course resembling multiple sclerosis. Saishin Igaku. 1976;31:1394-401.

23. Alexander EL, Ranzenbach MR, Kumar AJ, Kozachuk WE, Rosenbaum AE, Patronas N, et al. Anti-Ro(SS-A) autoantibodies in central nervous system disease associated with Sjögren's syndrome (CNS-SS): clinical, neuroimaging, and angiographic correlates. Neurology. 1994;44(5):899-908.

24. Yang JM, Heo H, Park SW. Relationship between retinal morphological findings and autoantibody profile in primary Sjögren's syndrome. Jpn J Ophthalmol. 2014:58(4):359-68.

25. Nakashima I, Takahashi T, Cree BA, Kim HJ, Suzuki C, Genain CP, et al. Transient increases in anti-aquaporin- 4 antibody titers following rituximab treatment in neuromyelitis optica, in association with elevated serum BAFF levels. J Clin Neurosci. 2011;18(7):997-8.

26. Diamond B, Huerta PT, Mina-Osorio P, Kowal C, Volpe BT. Losing your nerves? Maybe it's the antibodies. Nat Rev Immunol. 2009;9(6):449-56.

27. Denoyer A, Rabut G, Baudouin C. Tear film aberration dynamics and vision-related quality of life in patients with dry eye disease. Ophthalmology. 2012;119(9):1811-8.

28. Zhang Y, Potvin R, Gong L. A study of the short-term effect of artificial tears on contrast sensitivity in patients with Sjögren's syndrome. Invest Ophthalmol Vis Sci. 2013;54(13): 7977-82.

29. Yavuz S, Asfuroğlu E, Bicakcigil M, Toker E. Hydroxychloroquine improves dry eye symptoms of patients with primary Sjogren's syndrome. Rheumatol Int. 2011;31(8): 1045-9.

30. Rihl M, Ulbricht K, Schmidt RE, Witte T. Treatment of sicca symptoms with hydroxychloroquine in patients with Sjögren's syndrome. Rheumatology (Oxford). 2009;48(7): 796-9.

31. Mumcu G, Biçakçigil M, Yilmaz N, Ozay H, Karaçayli U, Cimilli H, et al. Salivary and serum B-cell activating factor (BAFF) levels after hydroxychloroquine treatment in primary Sjögren's syndrome. Oral Health Prev Dent. 2013;11(3):229-34.

32. Pasadhika S, Fishman GA. Effects of chronic exposure to hydroxychloroquine or chloroquine on inner retinal structures. Eye (Lond). 2010;24(2):340-6.

33. Ragheb S, Li Y, Simon K, VanHaerents S, Galimberti D, De Riz M, et al. Multiple sclerosis: BAFF and CXCL13 in cerebrospinal fluid. Mult Scler. 2011;17(7):819-29. 